\title{
Efficacy of Retreats on Resident Physician Well- being as Measured by Maslach Burnout Index Analysis: a Cross-sectional Study
}

\section{Kristyn N McLeod}

Mayo Clinic Minnesota

Shelby L Hopp

Mayo Clinic Minnesota

Emily J Woods

Mayo Clinic Minnesota

Christine M Lohse

Mayo Clinic Minnesota

\section{Fernanda Bellolio}

Mayo Clinic Minnesota

Nicole J Battaglioli

Emory Healthcare

James E Colletti ( $\nabla$ colletti.james@mayo.edu )

Mayo Clinic Minnesota https://orcid.org/0000-0003-1838-4703

\section{Research article}

Keywords: resident wellness, resident well-being, retreats, Maslach burnout index

Posted Date: June 2nd, 2020

DOI: https://doi.org/10.21203/rs.3.rs-30688/v1

License: (1) This work is licensed under a Creative Commons Attribution 4.0 International License. Read Full License 


\section{Abstract \\ Background}

Awareness of burnout has led residency programs to seek interventions to promote well-being, resiliency, camaraderie and social network development. Limited evidence exists on the efficacy of specific interventions. This study evaluated the efficacy of an emergency medicine residency program's semiannual retreat using serial administration of the Maslach burnout index and resident well-being survey.

\section{Methods}

Surveys were administered to all emergency medicine residents $(n=25)$ in July 2018 and before and after fall 2018 and winter 2019 retreats. Retreats included a meal, team building, and social networking opportunities (bowling, softball, snow tubing, and sledding). Comparisons of responses between baseline, pre-retreat, and post-retreat were evaluated using two-sample t, Wilcoxon rank sum, and Fisher exact tests.

\section{Results}

Sixteen emergency medicine residents (64\%) responded at baseline. Response rates on subsequent surveys ranged from $14(56 \%)$ to 21 (84\%). Nineteen percent of residents exhibited burnout at baseline. This peaked at $36 \%$ pre-winter retreat. Burnout decreased after each retreat (fall: $29-6 \%$, winter: $36-13 \%$ ). Mean Maslach burnout index subscores for emotional exhaustion (13 to 9) and depersonalization (7 to 5) decreased from baseline to post-fall retreat, but neither changed significantly over the entire study period (emotional exhaustion: 13 to 12, depersonalization: 7 to 6 ). Resident well-being survey pre-and postretreat responses were similar on all items.

\section{Conclusion}

Meaningful, but not statistically significant differences were detected on the Maslach burnout index and resident well-being survey in association with a retreat. Mean emotional exhaustion, depersonalization and burnout decreased after retreats. Larger studies would provide further insight into the significance of these trends.

\section{Introduction}

Burnout, a term encompassing feelings of emotional exhaustion, depersonalization, and reduced sense of personal accomplishment, ${ }^{1}$ is a problem across the continuum of medicine. Evidence suggests that burnout may peak during residency and fellowship along with increasing levels of depersonalization. ${ }^{2-4}$ This is particularly concerning given that depersonalization has been associated with worse patient outcomes. ${ }^{5,6}$ Moreover, burnout has been found to be worse in "front lines" specialties, including 
emergency medicine $(\mathrm{EM})^{7-9}$ where prevalence of burnout has been estimated to be as high as $65 \%{ }^{10}$ to $76 \%{ }^{11}$ among US EM residents.

These findings have led to a number of initiatives to explore contributing and mitigating factors both within medicine at large and within EM. These factors are found to fall into two umbrella categories: individual or organizational. Organizational level factors may include excessive workload, work inefficiency, lack of work-home integration, loss of control and autonomy, and loss of meaning from work. ${ }^{7}$ Additionally, relationships between the team members and social support at work have been identified as important factors influencing burnout. ${ }^{12,13}$ Individual factors contributing to burnout appear to have more variation and may include sex, age, educational debt, relationship status, age of children, and spouse or partner occupation. ${ }^{2,7,10,14}$ Adequate social support at the individual level has also been found to be associated with decreased levels of burnout. ${ }^{13,15}$

A natural response to these results has been a call for robust, multifaceted well-being programs. A metaanalysis of interventions to promote physician well-being found that efforts focused on both the individual and organization or structural levels have been effective for reducing burn out, and both approaches are likely necessary to develop sustainable programs. ${ }^{16}$ However, evidence on the efficacy of specific interventions is lacking. ${ }^{16-18}$

Among other efforts to promote well-being, the EM program at our institution holds semi-annual retreats for residents and faculty aimed at building social and community connectedness. We aimed to evaluate the efficacy of this specific intervention. We hypothesized that residency level, group retreats would improve or help maintain low levels of resident burnout and increased well-being as measured by serial administration of the Maslach Burnout Index (MBI) and a resident well-being survey (RWS).

\section{Methods}

Standardized guidelines for survey studies were followed ${ }^{19-21}$ and a protocol was written prior to the initiation of the research process.

\section{Target Population}

EM residents from a 3-year program.

\section{IRB Approval}

IRB approval was obtained prior to the initiation of this research study.

\section{Informed Consent}

Residents were asked to consent on the first page of the survey. Only those who consented answered the questions. Completing the survey was voluntary. All residents could participate in the retreats regardless of completion of the surveys. 


\section{Data Protection}

Data were securely stored in a password-protected server. Because of the sensitive nature of the responses, data were collected anonymously. However, the IRB requested that one team member have access to identified data if needed. The residents and medical student working on this project did not have access to identifiers. One faculty member had access to individual answers in case a resident with severe burnout was identified.

\section{Development and Training}

The $\mathrm{MBI}$ is a validated tool for assessing burnout. A license to administer the MBI Human Services Survey adapted for Medical Personnel and the interpretation manual were purchased.

MBI components are emotional exhaustion, depersonalization and personal accomplishment. Emotional exhaustion measures feelings of being emotionally overextended and exhausted by one's work; depersonalization measures an unfeeling and impersonal response toward patients; and personal accomplishment measures feelings of competence and successful achievement in one's work. It is a 22item survey with 9 items measuring emotional exhaustion, 5 items measuring depersonalization, and 8 items measuring personal accomplishment. ${ }^{1}$ Scoring of subcategories range from 0-54, 0-30, and 0-48 for emotional exhaustion, depersonalization, and personal accomplishment respectively. Each subcategory is considered individually and should not be combined. Categorizing each subcategory as low, medium, or high levels is not recommended. ${ }^{22}$ However, scores at the top end of the range of emotional exhaustion and depersonalization suggest higher levels of symptoms. Higher personal accomplishment scores represent higher sense of personal accomplishment. A "high" score in the category of emotional exhaustion $(\geq 27)$ or depersonalization $(\geq 10)$ is commonly used to determine burnout. ${ }^{2,3}$

The RWS (see additional file 1) was modeled after surveys validated to measure well-being among medical professionals. ${ }^{1}{ }^{123}$ Team members met with staff from our institution's survey research center to discuss, evaluate, and receive feedback regarding the survey.

\section{Piloting}

The questions for the RWS were tested with healthcare providers other than EM residents (e.g. medical students, off service residents rotating in the ED, and EM faculty).

\section{Refinement}

Feedback from the piloting was used to edit and refine the RWS survey. The questions were modified to reflect residents preferred language and match the interventions (retreats). With support from the survey research center, usability and technical functionality of the electronic questionnaire was tested before fielding the questionnaire.

\section{Recruitment Process and Contact Mode}


Residents were contacted by email by a co-resident to avoid any perceived coercion from a faculty invitation. Up to two reminders were sent for each administration of the survey (e.g. baseline, pre-retreat, and post-retreat). No monetary compensation was offered to participants.

\section{Sampling}

This study included a non-random sample of participants following purposive sampling, where a specific population was identified and only its members were included in the survey.

\section{Survey Administration}

The MBI survey was administered using REDCap and the RWS using SurveyMonkey. The MBI survey was administered via an electronic link to all EM residents $(n=25)$ in July 2018 to establish a baseline. Both $\mathrm{MBI}$ and RWS surveys were repeated before and after the fall 2018 and winter 2019 retreat.

\section{Intervention}

Retreats were considered interventions for this study. Each retreat was one half-day in length. The fall 2018 retreat included a casual meal as well as team building activities and social network opportunities such as bowling and softball. The winter 2019 retreat included a casual meal and outdoor winter activities such as snow tubing and sledding.

\section{Data Collection}

Data were collected in REDCap and SurveyMonkey and exported for analysis.

\section{Data Analysis and Statistical Methods}

Criteria for burnout was defined by a high score in either emotional exhaustion $(\geq 27)$ or depersonalization $(\geq 10)$ as is common among other studies using the MBI to evaluate physicians. ${ }^{2,3}$ Survey responses were classified as baseline (7/13/2018-7/23/2018), pre-fall retreat (8/21/2018-9/4/2018), post-fall retreat (9/5/2018-9/12/2018), pre-winter retreat (1/28/2019-2/4/2019) and post-winter retreat (2/5/2019$2 / 20 / 2019$ ). Continuous features were summarized with means and standard deviations (SD); categorical features were summarized with frequency counts and percentages. Comparisons of responses between baseline and pre-retreat, pre- and post-retreat, and baseline and post-winter retreat were evaluated using two-sample t, Wilcoxon rank sum, and Fischer exact tests. Statistical analyses were performed using SAS version 9.4 (SAS Institute; Cary, NC). All tests were two-sided. P-values $<0.05$ were considered statistically significant.

\section{Results}

Respondents were all residents in our institution's EM residency program. Select demographic information is summarized in Table 1. Figure 1 and Table 2 summarize responses to the MBI. Table 3 summarizes 
responses to the RWS. Sixteen residents (64\%) responded to the baseline administration of the MBI. Three of $16(19 \%)$ respondents exhibited evidence of burnout at baseline.

Table 1. Summary of Demographic Data of the Emergency Medicine Residency Program

\begin{tabular}{|c|l|}
\hline Demographic Variable & Total Program (N = 25) \\
\hline Female & 10 \\
\hline Level of Training, n (\%) & \\
\hline Post-Graduate Year 1 & $9(36)$ \\
\hline Post-Graduate Year 2 & $8(22)$ \\
\hline Post-Graduate Year 3 & $8(22)$ \\
\hline
\end{tabular}

Table 2. Summary of responses to MBI.

\begin{tabular}{|l|l|l|l|l|l|l|l|l|l|l|}
\hline MBI & Baseline & Pre-fall & Post-fall & Pre-winter & Post-winter & $P^{1}$ & $P^{2}$ & $P^{4}$ & $P^{5}$ \\
\hline Responses, $\mathbf{n}(\%)$ & $16(64)$ & $21(84)$ & $16(64)$ & $14(56)$ & $16(64)$ & & & & \\
\hline Scores, mean (SD) & & & & & & & & \\
\hline Emotional exhaustion & $13(7)$ & $13(8)$ & $9(7)$ & $12(9)$ & $12(10)$ & 0.90 & 0.19 & 0.71 & 0.95 & 0.78 \\
\hline Depersonalization & $7(5)$ & $7(5)$ & $5(3)$ & $8(6)$ & $6(4)$ & 0.92 & 0.11 & 0.41 & 0.19 & 0.56 \\
\hline Personal accomplishment & $41(6)$ & $40(6)$ & $41(6)$ & $41(6)$ & $43(3)$ & 0.69 & 0.54 & 0.95 & 0.41 & 0.36 \\
\hline Burnout, $\mathbf{n}(\%)$ & $3(19)$ & $6(29)$ & $1(6)$ & $5(36)$ & $2(13)$ & 0.70 & 0.11 & 0.42 & 0.20 & 1.0 \\
\hline
\end{tabular}

Response rate to each survey and mean subscore for each MBI component were calculated. Percentage of respondents meeting criteria for burnout was defined by a high score in either emotional exhaustion ( $\geq 27)$ or in depersonalization $(\geq 10) \cdot{ }^{2,3}$ Comparisons were made between multiple time points: $\mathrm{P}^{1}=$ baseline to pre-fall, $\mathrm{P}^{2}=$ pre-fall to post-fall, $\mathrm{P}^{3}=$ baseline to pre-winter, $\mathrm{P}^{4}=$ pre-winter to post-winter, $\mathrm{P}^{5}=$ baseline to post-winter. $(\mathrm{MBI}=$ Maslach Burnout Index)

\section{Fall Retreat}

There were 21 (84\%) and 16 (64\%), respondents for the pre- and post-fall retreat MBI administrations, respectively. Mean $\mathrm{MBI}$ subscores for emotional exhaustion were the same (13) from baseline to preretreat and decreased from pre- to post-retreat (13 to 9, $p=0.19$ ). Depersonalization decreased from pre- to post-retreat ( 7 to $5, p=0.11$ ). The percentage of residents meeting criteria for burnout increased from $19 \%$ at baseline to $29 \%$ during the pre-fall period. This decreased to $6 \%$ during the post-fall period. No statistically significant differences in burnout were found between baseline and pre-fall or between preand post-fall MBI administrations. 
Nineteen (76\%) and 20 (80\%) residents responded to the pre- and post-fall RWS administrations, respectively. The majority of residents responded agree or strongly agree to all items (95\% to 100\%). Five percent of respondents reported disagreement with statements 2 through 5 on pre-fall, post-fall, or both surveys. No statistically significant differences were found between pre- and post-retreat responses on any item $(p=1.0)$.

Table 3. Summary of Responses to the RWS.

\begin{tabular}{|l|c|c|c|c|}
\hline RWS & Pre-fall & Post-fall & Pre-winter & Post-winter \\
\hline Responses, n (\%) & 19 (76) & 20 (80) & 17 (68) & 14 (56) \\
\hline Agree/Strongly Agree (\%) & & & & \\
\hline 1. I feel that my residency program cares about me as a person. & 100 & 100 & 100 & 100 \\
\hline 2. I feel that my residency program encourages my development. & 100 & 95 & 94 & 93 \\
\hline 3. I feel valued at work. & & & & 100 \\
\hline 4. I feel valued by my co-workers. & & 95 & 100 & 100 \\
\hline
\end{tabular}

'he RWS was administered to all emergency medicine residents in our program before and after the fall 2018 and winter 2019 retreats to evaluate for motional and relational aspects of being a resident. (RWS $=$ Resident Well-Being Survey) ${ }^{*}$ For all administrations of RWS, $\mathrm{p}=1.0$ between responses re- and post-retreat.

\section{Winter Retreat}

There were 14 (56\%) and 16 (64\%) respondents to the pre- and post-winter retreat MBI administrations, respectively. Mean $\mathrm{MBI}$ subscores for emotional exhaustion were similar between baseline and pre-winter retreat $(13$ to $12, p=0.71)$ and the same between pre- and post-winter retreat $(12, p=0.95)$.

Depersonalization was similar between baseline and pre-winter retreat $(7$ to $8, p=0.41)$ and decreased from pre- to post-winter retreat ( 8 to $6, p=0.19$ ). While only $6 \%$ of resident respondents demonstrated burnout after the fall retreat, this increased to $36 \%$ in the pre-winter retreat period and decreased to $13 \%$ post-winter retreat. No statistically significant differences in burnout were identified between baseline and pre-winter or pre- and post-winter MBI administrations. 
There were 17 (68\%) and 14 (56\%) respondents to the pre- and post-winter retreat RWS administrations, respectively. The majority of residents responded agree or strongly agree to all questions ( $93 \%$ to $100 \%$ ). One of $17(6 \%)$ pre-winter retreat and one of $14(7 \%)$ post-winter respondents disagreed with the statement: "I feel that my residency program encourages my development." No statistically significant differences were found between pre- and post-winter retreat responses on any item $(p=1.0)$.

\section{Baseline to Post-Winter Retreat}

Over the entire study period from July 2018 to February 2019, mean MBI subscores for emotional exhaustion (13 to $12, p=0.78$ ) and for depersonalization ( 7 to $6, p=0.56$ ) remained similar. At baseline, $19 \%$ of resident respondents exhibited burnout. Following the winter retreat, $13 \%$ did $(p=1.0)$.

\section{Resident Commentary}

Free-responses regarding most liked aspects of retreats included dedicated time for bonding with peers and faculty as well as socializing outside of a clinical setting. Least liked aspects of the retreat included the weather (i.e. rain, cold temperatures) and scheduling, particularly for residents working night shifts before or after the retreat. Other comments mentioned the retreats were too short.

\section{Discussion}

This is a single center survey study to evaluate the effect of retreats on residents' well-being. Overall, levels of burnout were low and well-being was high among residents. Several important trends were noted; however, because of our small sample size, these results were not statistically significant. Mean depersonalization scores decreased after each retreat. The number of residents meeting criteria for burnout increased before and decreased following each retreat. This suggests that retreats may target depersonalization more than emotional exhaustion as a mechanism of decreasing burnout. While this study does not show prevention of burnout, levels of burnout decreased after each retreat. This suggests retreats may be a useful intervention for acutely decreasing levels of depersonalization and thus burnout among EM residents. Additionally, residents' sense of well-being as measured by the RWS remained similar before and after retreats. This might be secondary to high levels of resident well-being at baseline, the multifactorial and complex nature of well-being, and the short length of our intervention (half-day).

While the MBI score has three components, studies have found emotional exhaustion and depersonalization are most informative with regard to burnout among physicians. ${ }^{1,2,6}$ Thus, burnout was defined by high scores in either of these domains. In this study, $19 \%$ of baseline respondents met criteria for burnout. Burnout peaked at $36 \%$ of pre-winter retreat respondents. These values are significantly lower than previously reported prevalence of burnout among EM residents of greater than $60 \%{ }^{10,11}$ and among residents across various specialties of $44-76 \%{ }^{2}, 3,6,24$ Despite low levels of burnout overall, a promising trend emerged: though increasing in the interim, burnout decreased following each retreat. This is important because burnout has been associated with adverse outcomes, $5,6,25$ and decreasing burnout by 
increments as small as one point on the $\mathrm{MBI}$ has been associated with meaningful improvements in resident-perceived medical errors. ${ }^{25}$

To further characterize the effect of retreats, we also explored the subcategories of the MBI. Mean personal accomplishment scores were consistently high and similar to previously reported data. ${ }^{3,25}$ Mean emotional exhaustion trended down from baseline to post-fall retreat, but when looked at over the entire study period remained similar. Mean emotional exhaustion values were lower for our study group than those previously reported. ${ }^{3,25}$ Additionally, mean depersonalization scores were similar to previously reported values ${ }^{3,25}$ and did not change significantly over the study period. However, they offered significant insight. Mean depersonalization scores followed similar trends to burnout, decreasing after each retreat. That is, we can conclude that the retreats effect on depersonalization was a contributor to decreased percentages of burnout among our EM residents. This trend is consistent with interventions among other specialties showing decreased depersonalization scores. ${ }^{16,26}$ Additionally, it is worth reiterating that depersonalization has been shown to be correlated to worse patient outcomes. Thus, resident retreats aimed at improving social interactions may be valuable.

While often colloquially used interchangeably, a distinction can be made between the terms burnout and well-being. Burnout is well-defined as a state encompassing feelings of emotional exhaustion, depersonalization, and reduced sense of personal accomplishment. ${ }^{1}$ The definition of well-being is less agreed upon. A critical component of well-being may be a lack of burnout, but there are likely other important contributing factors. ${ }^{13,27}$ We implemented the RWS to explore additional factors of well-being such as the emotional and relational aspects of residency. The majority of residents agreed or strongly agreed with statements regarding feeling valued and feeling cared for by the residency program. However, following each retreat, there was a downtrend in agreement with the statement regarding feeling as though the residency program encourages development. This finding is difficult to interpret, though may offer a future avenue for improving resident well-being through focused mentorship on this topic.

Additionally, on the RWS, residents responded to free-response questions asking for positive and negative feedback about retreats. Most comments revolved around the same theme: residents valued dedicated time for socialization with both their peers and faculty in a non-medical context. Discontent primarily revolved around difficulty attending retreats because of scheduling (i.e. working the night before or after the retreat). These findings are consistent with a previous study that found that, among other factors, having a supportive work environment, getting together with other residents, and talking with a faculty or physician mentor were associated with decreased burnout. ${ }^{13}$

The overarching results of the RWS suggest that our EM residents are satisfied with and have a high level of overall well-being. This is congruent with our findings of lower than average percentages of burnout.

\section{Limitations}


The study was limited by the small sample size and response rates, which may have prevented detection of subtle changes in burnout and well-being. Additionally, the percentage of respondents exhibiting burnout should be interpreted carefully as they do not represent all residents in the program. It is possible that less burnt out residents were more likely to respond and thus, our results would be biased. These factors may limit the generalizability of the study. Moreover, because data were collected anonymously, we were not able to link participants across time points, which may have provided more specific data.

\section{Conclusions}

While changes in MBI and RWS scores following retreats were not statistically significant, promising trends were noted. Mean emotional exhaustion decreased post-fall retreat while mean depersonalization and burnout decreased after each retreat. While this study does not show prevention of burnout, the trends suggest retreats may be a useful intervention for acutely decreasing burnout, specifically the depersonalization component, among EM residents. Larger scale studies powered to detect subtle changes would provide further insight into the significance of these trends.

\section{List Of Abbreviation}

$\mathrm{EM}=$ emergency medicine

$\mathrm{MBI}=$ Maslach burnout index

RWS $=$ resident well-being survey

$\mathrm{SD}=$ standard deviation

\section{Declarations}

\section{Ethics approval and consent to participate}

This study was approved by the Institutional Review Board and was determined to be exempt.

\section{Consent for publication}

Not applicable.

\section{Availability of data and materials}

The datasets generated and/or analysed during the current study are not publicily available due to the need to protect anonymity of the subjects, but are available from the corresponding author on reasonable request. Maslach Burnout Index and interpretation guide can be purchased for use at mindgarden.com

\section{Competing Interests}


The authors declare that they have no competing interests.

\section{Funding}

We received the Endowment for Education Research Award from the Office for Applied Scholarship and Science Mayo Clinic grant for this research. The Office for Applied Scholarship and Science had no role in design, collection of data, analysis or interpretation of data, or writing of the manuscript.

\section{Authors' contributions}

All authors contributed to the study design. SH and ES implemented the intervention and developed the resident wellness survey. $\mathrm{CL}$ provided data analysis. KM interpreted the data and prepared the initial manuscript. All authors provided critical revisions. All authors read and approved the final manuscript.

\section{Acknowledgements}

Not applicable.

\section{References}

1. Maslach C, Jackson SE, Leiter MP, Schaufeli WB, Schwab RL. Maslach burnout inventory: Consulting Psychologists Press Palo Alto, CA; 1986.

2. Dyrbye $L$, Shanafelt T. A narrative review on burnout experienced by medical students and residents. Med Educ. 2016;50(1):132-49.

3. Dyrbye LN, West CP, Satele D, Boone S, Tan L, Sloan J, et al. Burnout among US medical students, residents, and early career physicians relative to the general US population. Acad Med. 2014;89(3):443-51.

4. Lu DW, Dresden S, McCloskey C, Branzetti J, Gisondi MA. Impact of burnout on self-reported patient care among emergency physicians. West J Emerg Med. 2015;16(7):996.

5. Panagioti M, Geraghty K, Johnson J, Zhou A, Panagopoulou E, Chew-Graham C, et al. Association between physician burnout and patient safety, professionalism, and patient satisfaction: a systematic review and meta-analysis. JAMA internal medicine. 2018;178(10):1317-30.

6. Shanafelt TD, Bradley KA, Wipf JE, Back AL. Burnout and self-reported patient care in an internal medicine residency program. Ann Intern Med. 2002;136(5):358-67.

7. West CP, Dyrbye LN, Shanafelt TD. Physician burnout: contributors, consequences and solutions. J Intern Med. 2018;283(6):516-29.

8. Shanafelt TD, Boone S, Tan L, Dyrbye LN, Sotile W, Satele D, et al. Burnout and satisfaction with worklife balance among US physicians relative to the general US population. Arch Intern Med. 2012;172(18):1377-85.

9. Dyrbye LN, Burke SE, Hardeman RR, Herrin J, Wittlin NM, Yeazel M, et al. Association of clinical specialty with symptoms of burnout and career choice regret among US resident physicians. JAMA. 
2018;320(11):1114-30.

10. Kimo Takayesu J, Ramoska EA, Clark TR, Hansoti B, Dougherty J, Freeman W, et al. Factors associated with burnout during emergency medicine residency. Acad Emerg Med. 2014;21(9):1031-5.

11. Lin M, Battaglioli N, Melamed M, Mott SE, Chung AS, Robinson DW. High Prevalence of Burnout Among US Emergency Medicine Residents: Results From the 2017 National Emergency Medicine Wellness Survey. Ann Emerg Med. 2019;74(5):682-90.

12. Ismail MNBM, Johnson SL, Weaver SJ, Wu AW, Gielen AC. Factors influencing burn-out among resident physicians and the solutions they recommend. Postgrad Med J. 2018;94(1115):540-2.

13. Eckleberry-Hunt J, Lick D, Boura J, Hunt R, Balasubramaniam M, Mulhem E, et al. An exploratory study of resident burnout and wellness. Acad Med. 2009;84(2):269-77.

14. Prins JT, Gazendam-Donofrio SM, Tubben BJ, Van Der Heijden FM, Van De Wiel HB, HoekstraWeebers JE. Burnout in medical residents: a review. Med Educ. 2007;41(8):788-800.

15. Kennedy B, Levine M, Goldman ML, Abhyankar L, Konopasek L. Social Support Network Outreach: A No-Cost Intervention to Improve Resident Well-Being. The Accreditation Council for Graduate Medical Education; 2017.

16. West CP, Dyrbye LN, Erwin PJ, Shanafelt TD. Interventions to prevent and reduce physician burnout: a systematic review and meta-analysis. The Lancet. 2016;388(10057):2272-81.

17. Williams D, Tricomi G, Gupta J, Janise A. Efficacy of burnout interventions in the medical education pipeline. Acad Psychiatry. 2015;39(1):47-54.

18. Raj KS. Well-being in residency: a systematic review. J Grad Med Educ. 2016;8(5):674-84.

19. Kelley K, Clark B, Brown V, Sitzia J. Good practice in the conduct and reporting of survey research. Int J Qual Health Care. 2003;15(3):261-6.

20. Eysenbach G. Improving the quality of Web surveys: the Checklist for Reporting Results of Internet ESurveys (CHERRIES). J Med Internet Res. 2004;6(3):e34.

21. Burns KE, Duffett M, Kho ME, Meade MO, Adhikari NK, Sinuff T, et al. A guide for the design and conduct of self-administered surveys of clinicians. CMAJ. 2008;179(3):245-52.

22. The problem with Cut-Offs for the Maslach Burnout Inventory. https://www.mindgarden.com/documents/MBI-Cutoff-Caveat.pdf. Accessed 11 July 2019.

23. Trockel M, Bohman B, Lesure E, Hamidi MS, Welle D, Roberts L, et al. A Brief Instrument to Assess Both Burnout and Professional Fulfillment in Physicians: Reliability and Validity, Including Correlation with Self-Reported Medical Errors, in a Sample of Resident and Practicing Physicians. Acad Psychiatry. 2018;42(1):11-24.

24. Thomas NK. Resident burnout. JAMA. 2004;292(23):2880-9.

25. West CP, Huschka MM, Novotny PJ, Sloan JA, Kolars JC, Habermann TM, et al. Association of perceived medical errors with resident distress and empathy: a prospective longitudinal study. JAMA. 2006;296(9):1071-8. 
26. Panagioti M, Panagopoulou E, Bower P, Lewith G, Kontopantelis E, Chew-Graham C, et al. Controlled interventions to reduce burnout in physicians: a systematic review and meta-analysis. JAMA internal medicine. 2017;177(2):195-205.

27. Eckleberry-Hunt J, Van Dyke A, Lick D, Tucciarone J. Changing the conversation from burnout to wellness: physician well-being in residency training programs. J Grad Med Educ. 2009;1(2):225-30.

\section{Additional Files}

\section{Additional File 1}

File format: .docx

Title of data: Resident Well-Being Survey

Description of data: Includes survey provided to residents to evaluate for emotional and relational aspects of being a resident.

\section{Figures}




\section{Emotional exhaustion Depersonalization}

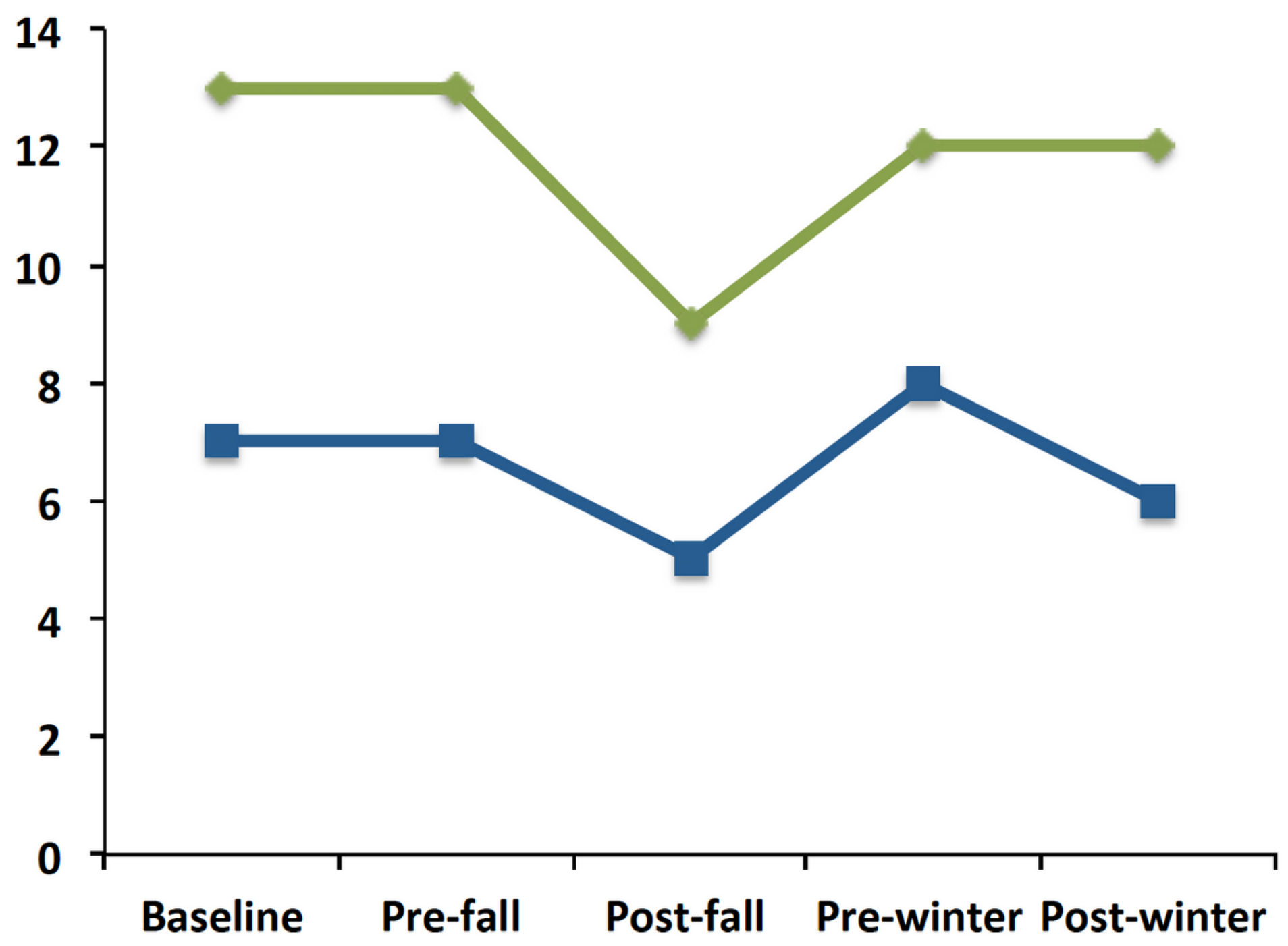

Figure 1

Mean MBI Scores from July 2018 to February 2019. There were 5 total administrations of the MBI. Subscores for emotional exhaustion and depersonalization were trended over time. (MBI = Maslach Burnout Index)

\section{Supplementary Files}

This is a list of supplementary files associated with this preprint. Click to download.

- 4Additionalfile12.docx 